\title{
Evidencias sobre una nueva especie del género Dirofilaria en perros de Neuquén, Argentina
}

\author{
Evidences on a new species of the genus Dirofilaria in dogs from Neuquén, \\ Argentina
}

\author{
Vezzani $D^{1,2^{\star}}$, Moré $\mathrm{G}^{2,3}$, Eiras $\mathrm{DF}^{3,4}$ \\ Instituto Multidisciplinario sobre Ecosistemas y Desarrollo Sustentable, Facultad de Ciencias Exactas, \\ UNICEN, Tandil; 2. Consejo Nacional de Investigaciones Científicas y Técnicas (CONICET); 3. Laboratorio \\ de Inmunoparasitología, Facultad de Ciencias Veterinarias, Universidad Nacional La Plata 4. Laboratorio \\ DIAP, Banfield, provincia de Buenos Aires. \\ *Correo electrónico del autor: dvezzani@gmail.com
}

\begin{abstract}
Resumen: La dirofilariasis canina en Argentina se extiende desde la provincia de Buenos Aires hacia el norte. En todos los casos documentados, el agente etiológico es el gusano del corazón del perro, Dirofilaria immitis, única especie del género identificada como causal de infecciones naturales autóctonas en el país. En este estudio, se presentan evidencias morfológicas, serológicas y moleculares de la infección de otra especie del género Dirofilaria en 8 perros de la ciudad de Neuquén, en el extremo norte de la Patagonia. Las microfilarias observadas tuvieron una media de $370 \mu \mathrm{m}$ de largo y $7,1 \mu \mathrm{m}$ de ancho. Las secuencias obtenidas mostraron homologías inferiores al $95 \%$ con otras secuencias de filáridos reportadas en el GenBank.
\end{abstract}

Palabras clave: filáridos, perros, Patagonia, Argentina, dirofilariasis

\begin{abstract}
Canine dirofilariasis in Argentina extends from Buenos Aires province to the North. All documented cases were due to the dog heartworm, Dirofilaria immitis, the unique species recorded in natural infected dogs in the country. In this study, we present morphologic, serologic and molecular evidences of the infection with another Dirofilaria species in 8 dogs from Neuquén city, in the northern extreme of Patagonia. The observed microfilariae had a mean of $370 \mu \mathrm{m}$ long and $7.1 \mu \mathrm{m}$ wide. The sequences obtained showed homologies lower than $95 \%$ with other filarid sequences reported in the Genbank.
\end{abstract}

Key words: filarid, dogs, Patagonia, Argentina, dirofilariasis 


\section{Introducción}

La dirofilariasis canina es una enfermedad de gran importancia veterinaria a nivel mundial causada por nematodos del género Dirofilaria Railliet \& Henry, 1911 (Orden Spirurida, Familia Onchocercidae). Los principales agentes etiológicos son Dirofilaria immitis Leidy, 1856, en regiones templadas y tropicales de todo el mundo, y Dirofilaria repens Railliet \& Henry, 1911, en Europa, África y Asia (Simón et al., 2012; Dantes-Torres \& Otranto, 2013). Actualmente el género está compuesto por 27 especies válidas y 15 cuestionables (Canestri Trotti et al., 1997; DantesTorres \& Otranto, 2013). En el continente americano, $D$. immitis es el responsable indiscutido tanto de la dirofilariasis canina como de la dirofilariasis pulmonar humana. Sin embargo, al menos otras 11 especies están bien documentadas en fauna silvestre del continente: $D$. freitasi Machado de Mendonca, 1949, D. Iutrae Orihel \& Beaver, 1974, D. cancrivori Eberhard, 1978, D. acutiuscula Molin, 1858, D. macrodemos Eberhard, 1978, D. panamensis Eberhard, 1978, D. subdermata Monnig, 1924, D. tenuis Chandler, 1942, D. ursi Yamaguti, 1941, D. striata Molin, 1858, y D. spectans Freitas y Lent, 1949 (Canestri Trotti et al., 1997; Vicente et al., 1997).

En Argentina, la dirofilariasis canina por $D$. immitis se extiende en 11 provincias: Salta, Formosa, Chaco, Misiones, Corrientes, Entre Ríos, Santa Fe, Santiago del Estero, Córdoba, Mendoza y Buenos Aires (Vezzani et al., 2006; Vezzani \& Eiras, 2016). Si bien los registros de casos señalan a la ciudad de La Plata y sus alrededores como el límite sur de distribución del parásito en Sudamérica, los modelos teóricos basados principalmente en la temperatura sugieren que existen las condiciones climáticas adecuadas para su transmisión en el norte de la Patagonia (Cuervo et al., 2015; Vezzani \& Carbajo, 2006). Hasta el presente ninguna otra especie del género ha sido confirmada en nuestro país en infecciones naturales autóctonas. El objetivo de este trabajo es reportar los hallazgos microscópicos y moleculares acerca de una especie del género Dirofilaria, distinta a $D$. immitis, en perros de la ciudad de Neuquén.

\section{Materiales y métodos}

Se analizaron muestras de sangre pertenecientes a 8 perros microfilarémicos que asistieron a consulta veterinaria durante 2011-2013 en la ciudad de Neuquén. Esta ciudad se encuentra ubicada en $38^{\circ} 57^{\prime} 06^{\prime \prime} S 68^{\circ} 04^{\prime} 28^{\prime \prime} \mathrm{O}$, aproximadamente $500 \mathrm{~km}$ al sur del límite conocido de distribución de $D$. immitis. Los pacientes fueron identificados como positivos para microfilarias durante la observación de la interfase del capilar microhematocrito en la rutina de laboratorio. Las muestras fueron recolectadas en anticoagulante
EDTA, conservadas a $4{ }^{\circ} \mathrm{C}$ y remitidas al Laboratorio de Inmunoparasitología de la FCV-UNLP para su caracterización.

Se realizaron mediciones morfológicas en microfilarias (10 larvas por muestra) recuperadas del test de Knott modificado, de acuerdo con lo indicado por Soulsby (1987). La sangre remanente se conservó a $-20^{\circ} \mathrm{C}$ para la extracción de ADN y realización de pruebas moleculares. Además, se recolectaron muestras de sangre sin anticoagulante para la obtención de suero y realización de pruebas serológicas rápidas para la detección de antígeno específico de las hembras adultas de D. immitis (FASTest $®$ DIRO, Megacor, Austria).

El ADN de las muestras de sangre entera se extrajo utilizando el kit comercial Wizard $®$ Genomic DNA Purification (Promega, EE.UU.) siguiendo las instrucciones del fabricante, con el agregado de 20 $\mu \mathrm{l}$ de proteinasa $\mathrm{K}(20 \mathrm{mg} / \mathrm{ml}$; Promega, EE.UU) al buffer de lisis nuclear, incubando a $55^{\circ} \mathrm{C}$ overnight. Cada rutina incluyó un tubo sin muestra, pero conteniendo todas las soluciones del kit, como control de extracción.

Se realizaron dos técnicas de PCR con targets diferentes. En la primera se utilizaron los cebadores DIDR-F1 y DIDR-R1 con los que se amplifican fragmentos de las subunidades ribosomales 5.8S-ITS2$28 S$ de diferentes filáridos (Rishniw et al., 2006), denominados de aquí en adelante como Panfilaria. El protocolo de amplificación fue $94^{\circ} \mathrm{C}$ durante 4 min y luego 35 ciclos de: $94^{\circ} \mathrm{C}$ por $30 \mathrm{~s}, 60^{\circ} \mathrm{C}$ por $30 \mathrm{~s}$ y $72{ }^{\circ} \mathrm{C}$ por $45 \mathrm{~s}$. Por último, la extensión final se realizó a $72{ }^{\circ} \mathrm{C}$ durante $7 \mathrm{~min}$. En la segunda técnica se utilizaron los cebadores COIF y COIR, que amplifican un fragmento del gen de subunidad I de la citocromooxidasa mitocondrial (COI). La amplificación en este caso se realizó en las siguientes condiciones: $94{ }^{\circ} \mathrm{C}$ durante 4 min y luego 40 ciclos de: $94^{\circ} \mathrm{C}$ durante $45 \mathrm{~s}$, $54{ }^{\circ} \mathrm{C}$ durante $45 \mathrm{~s}$ y $72{ }^{\circ} \mathrm{C}$ durante $45 \mathrm{~s}$. La extensión final se realizó a $72^{\circ} \mathrm{C}$ durante $7 \mathrm{~min}$ (Casiraghi et al., 2001, 2006). Todas las rutinas de PCR se llevaron a cabo con controles positivos ( $D$. immitis), control de extracción (como negativo) y una muestra sin ADN (NTC= no template control).

Los productos de amplificación fueron revelados en geles de agarosa al 1,5\% y fueron observados en el transiluminador de luz azul. La técnica Panfilaria se caracteriza por la obtención de fragmentos de diferente longitud de acuerdo con la especie de filárido hallado (Rishniw et al., 2006). En el protocolo COI se analiza la presencia de una banda de aproximadamente 650 pares de bases (pb) para diferentes filáridos, diferenciables mediante RFLP (restriction fragment length polymorphism) o secuenciación (Casiraghi et al., 2001, 2006). 
Los productos de amplificación de ambas técnicas fueron purificados con el kit Wizard® SV Gel and PCR Clean-Up System (Promega, EE.UU) y remitidos para secuenciación al Instituto de Biotecnología de la Unidad de Genómica (Estación Experimental INTA-Castelar). Las secuencias fueron alineadas y analizadas mediante el software GENEIOUS (Versión R9) y comparadas con otras disponibles en el GenBank mediante la herramienta BLASTn (Basic Local Alignment Search Tool) del NCBI (National Center for Biotechnology Information) disponible en línea. (https:// blast.ncbi.nlm.nih.gov/Blast.cgi).

\section{Resultados}

Los 8 perros microfilarémicos resultaron negativos para $D$. immitis en los estudios serológicos. En las mediciones de las microfilarias se registró una media de $370 \mu \mathrm{m}$ de largo (mínimo: 339, máximo: 411) y $7,1 \mu \mathrm{m}$ de ancho, con el extremo anterior redondeado y el posterior ahusado. En los extendidos de sangre coloreados se observó que las primeras células somáticas se encontraban muy próximas al extremo anterior de las microfilarias (Fig. 1), rasgo de similitud con $D$. repens pero no con $D$. immitis, en las que las primeras células aparecen un poco más atrás.

Todas las muestras fueron positivas para la detección de ADN de filáridos mediante PCR en ambas técnicas utilizadas. Para la PCR Panfilaria se obser- varon fragmentos de $\sim 500 \mathrm{pb}$, valor intermedio entre los esperados para $D$. immitis (542 pb) y $D$. repens $(484 \mathrm{pb})$. Se obtuvo un total de 5 secuencias de PCR Panfilaria y 2 de COI. Las secuencias correspondieron a muestras de 5 animales y cada grupo de secuencias de cada gen presentó una homología mayor al $99 \%$. Sin embargo, todas las secuencias mostraron homologías inferiores al $95 \%$ con otras secuencias de filáridos reportadas en el GenBank. Las secuencias de la PCR Panfilaria evidenciaron una homología del $91 \%$ con secuencias obtenidas de $D$. repens en Túnez (KR676387) y de D. immitis en Portugal (LN626260); ambas secuencias corresponden a estudios no publicados. Por otra parte, las secuencias obtenidas de la PCR de COI mostraron un $94 \%$ de homología con la secuencia de Dirofilaria sp. "hongkongensis" (KX265050), 93\% con D. repens de un caso humano en República Checa (KR998259) y $91 \%$ con D. immitis obtenida de mosquitos en España (LC107816). Las secuencias obtenidas para Panfilaria y $\mathrm{CO}$ fueron depositadas en el GenBank como Dirofilaria sp., con los números de acceso KY085962 y KY085963, respectivamente.

\section{Discusión y conclusiones}

La dirofilariasis canina es una enfermedad totalmente desconocida en la Patagonia. La presente comunicación es, sin duda, la primera sobre una infección canina por Dirofilaria en la región. También es el primer

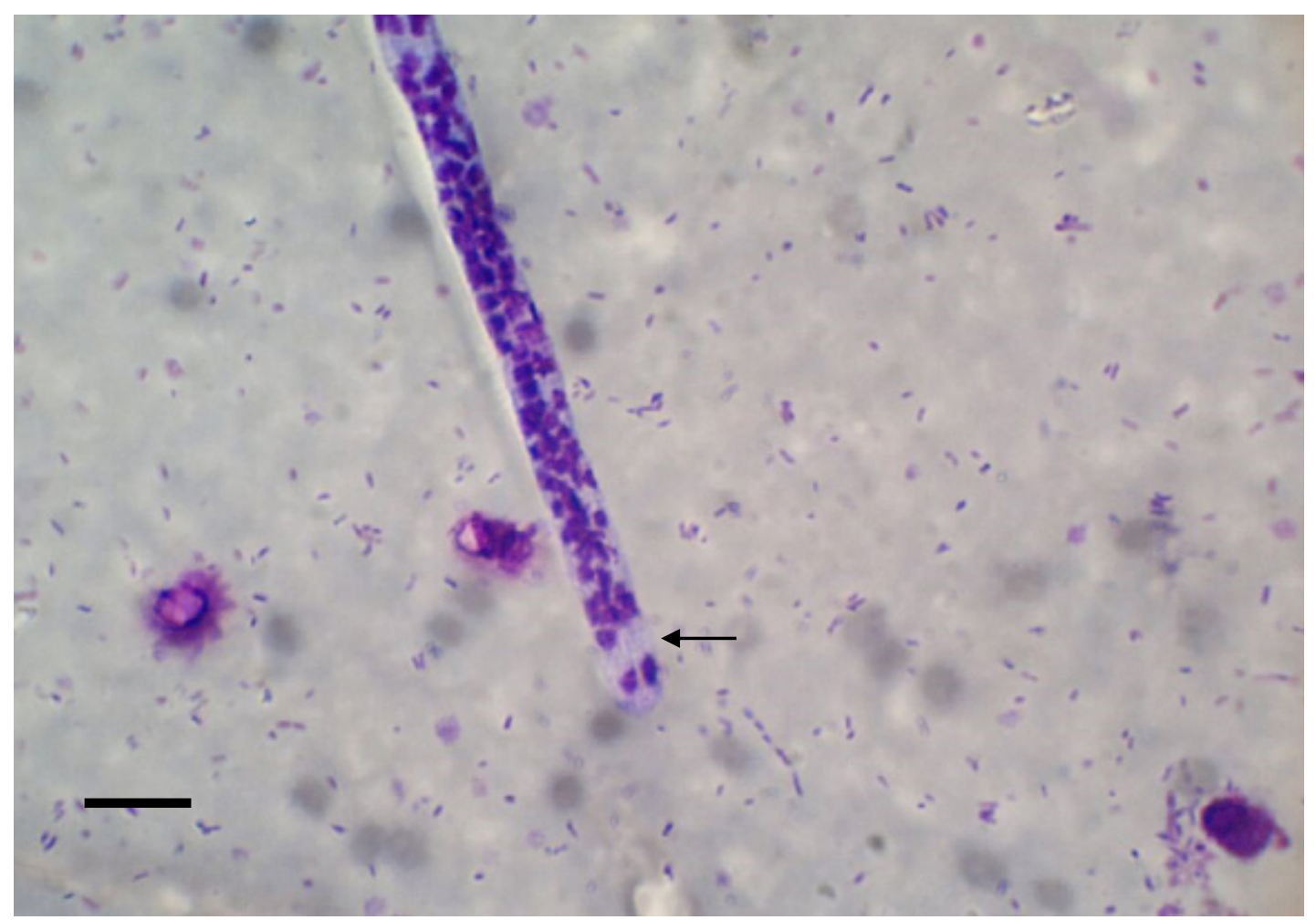

Figura 1. Detalle del extremo anterior de la microfilaria de Dirofilaria sp. hallada en perros de Neuquén. Extendido sanguíneo coloreado con May-Grünwald Giemsa (1000x). La flecha indica las primeras células somáticas cercanas al extremo anterior. Barra: $10 \mu \mathrm{m}$. 
estudio que demuestra, mediante distintas técnicas, la presencia de una especie del género distinta a $D$. immitis en nuestro país. Las mediciones morfológicas de las microfilarias encontradas registraron valores muy lejanos a $D$. immitis ( $301,7 \mu \mathrm{m}$ de largo y $6,3 \mu \mathrm{m}$ de ancho; Magnis et al., 2013). La longitud media de $370 \mu \mathrm{m}$ observada es muy superior a la de las microfilarias de las especies más comunes descriptas en caninos, con la excepción de Dipetalonema grassi Noe, 1907, la cual tiene una media de $570 \mu \mathrm{m}$ (Soulsby, 1987). La homología de las secuencias obtenidas indicaría que las microfilarias halladas se corresponden con una misma especie en todos los casos de Neuquén y que no se corresponderían con $D$. immitis ni con $D$. repens. Los resultados serológicos negativos obtenidos en las 8 muestras microfilarémicas, junto con las secuenciaciones obtenidas, indican claramente que la especie de filárido presente en los perros estudiados no es $D$. immitis. Por otra parte, dentro de la baja homología de secuencias mediante BLAST, detectamos una de las mayores homologías (93\%) con secuencias de $D$. repens, aunque esto no resulta suficiente ya que la homología esperada para identificación de especies debe superar el $98-99 \%$.

Recientemente, López et al. (2012) reportaron por primera vez una infección canina por Dirofilaria en Santiago de Chile. Los autores describen una potencial nueva especie, la cual es cercana en aspectos morfológicos y moleculares, aunque distinta, a $D$. repens. Si bien nuevas especies son sugeridas con cierta frecuencia, considerando el actual número de especies dudosas dentro del género, cualquier sugerencia de una nueva especie que no incluya una descripción genética y morfológica completa podría ser prematura (Dantes-Torres \& Otranto, 2013). En este sentido, más estudios son necesarios para avanzar sobre la identificación del filárido que hemos hallado en el extremo norte de nuestra Patagonia, el cual podría, o no, ser el mismo descripto recientemente en Chile.

\section{Agradecimientos}

Los autores agradecen a Andrea Varni del Laboratorio Veterinario LAVAC, San Martín 2275, Ciudad de Neuquén, Argentina, por la provisión de las muestras pertenecientes a los hallazgos descriptos en este trabajo. A Belén Craviotto y Gimena Rudchenco por la colaboración técnica.

\section{Conflicto de intereses}

Todos los autores declaran que no existe conflicto de intereses, incluyendo las relaciones financieras, personales o de otro tipo con otras personas u organizaciones que pudieran influir de manera inapropiada en el trabajo.

\section{Bibliografía}

Canestri Trotti G, Pampiglione S, Rivasi F. 1997. The species of the genus Dirofilaria Railliet \& Henry, 1911. Parassitologia. 39(4):369-374.

Casiraghi M, Anderson T, Bandi C, Bazzocchi C, Genchi C. 2001. A phylogenetic analysis of filarial nematodes: comparison with the phylogeny of Wolbachia endosymbionts. Parasitology. 122:93-103.

Casiraghi M, Bazzocchi C, Mortarino M, Ottina E, Genchi C. 2006. A simple molecular method for discriminating common filarial nematodes of dogs (Canis familiaris). Veterinary Parasitology. 141:368-372. doi:10.1016/j.vetpar.2006.06.006.

Cuervo PF, Rinaldi L, Cringoli G. 2015. Modeling the extrinsic incubation of Dirofilaria immitis in South America based on monthly and continuous climatic data. Veterinary Parasitology. 209:70-75. doi:10.1016/j.vetpar.2015.02.010.

Dantes-Torres F, Otranto D. 2013 Dirofilariosis in the Americas: a more virulent Dirofilaria immitis? Parasites \& Vectors. 6:288. doi: 10.1186/1756-3305-6-288.

López J, Valiente-Echeverría F, Carrasco M, Mercado R, Abarca K. 2012. Morphological and molecular identification of canine filariae in a semi-rural district of the metropolitan region in Chile. Revista Chilena de Infectología. 29:248-289. doi: 10.4067/S0716-10182012000300006.

Magnis J, Lorentz S, Guardone L, Grimm F, Magi M, Naucke TJ, Deplazes P. 2013. Morphometric analyses of canine blood microfilariae isolated by the Knott's test enables Dirofilaria immitis and D. repens species-specific and Acanthocheilonema (syn. Dipetalonema) genus-specific diagnosis. Parasites \& Vectors. 6:48. doi: 10.1186/1756-3305-6-48.

Rishniw M, Barr SC, Simpson KW, Frongillo MF, Franz M, Alpizar JLD. 2006. Discrimination between six species of canine microfilariae by a single polymerase chain reaction. Veterinary Parasitology. 135:305-314. doi:10.1016/j.vetpar.2005.10.013

Simón F, Siles-Lucal M, Morchón R, González-Miguel J, Mellado I, Carretón E, Montoya-Alonso JA. 2012. Human and animal dirofilariasis: the emergence of a zoonotic mosaic. Clinical Microbiology Reviews. 25:507-543. doi: 10.1128/ CMR.00012-12.

Soulsby EJL. 1987. Parasitología y enfermedades parasitarias en los animales domésticos. $7^{\text {a }}$ Ed. México DF, Nueva Interamericana.

Vezzani D, Carbajo AE. 2006. Spatial and temporal transmission risk of Dirofilaria immitis in Argentina. International Journal for Parasitology. 26:1463-1472. doi:10.1016/j.jpara.2006.08.012.

Vezzani D, Eiras DF, Wisnivesky C. 2006. Dirofilariasis in Argentina: Historical review and first report of Dirofilaria immitis in a natural mosquito population. Veterinary Parasitology. 136:259-273. doi:10.1016/j.vetpar.2005.10.026.

Vezzani D, Eiras F. Actualización sobre dirofilariasis en Argentina y el contexto en América. En: Berón CM, Campos RE, Gleiser RM, Díaz-Nieto LM, Salomón OD, Schweigmann N. 2016. Investigaciones sobre mosquitos en Argentina. Mar del Plata, Universidad Nacional de Mar del Plata. pp. 192-200.

Vicente JJ, Rodrigues HO, Gomes DC, Pinto RM. 1997. Nematóides do Brasil. Parte V: nematóides de mamíferos. Revista Brasileira de Zoologia. 14(Suppl 1):1-452. 